\title{
aniki
}

Revista Portuguesa da Imagem em Movimento

Portuguese Journal of the Moving Image

\section{Por Dentro das Imagens: O movimento do olhar e a vertigem do novo milénio Luís Mendonça $^{1}$}

Dias Branco, Sérgio. 2016. Por Dentro das Imagens - Obras de cinema. Ideias do cinema. Lisboa: Documenta. 160 pp.

Por Dentro das Imagens: Obras de Cinema, Ideias do Cinema não é um livro académico. Os textos reunidos, desde críticas para revistas a apresentações de filmes em sessões públicas, reportam-se a um período de descoberta na vida do autor, Sérgio Dias Branco (SDB). "Este livro arruma uma parte daquilo que foi a minha relação com o cinema através da escrita em determinado período da minha vida," disse-me em entrevista para o site de cinema À pala de Walsh (Mendonça 2016, s/p). Não se trata, contudo, de uma obra que olhe para trás, mas que, bem pelo contrário, reflete sobre o que persiste de um olhar passado no presente. Em "A Política dos Autores, Pensar a Solidão," o autor convoca Henri Langlois para definir o "olhar do crítico" como aquele que "prefigura o futuro," ao passo que o "olhar do historiador" é caracterizado por uma "posição de recuo" (Dias Branco 2016, 109). Por Dentro das Imagens é um livro de crítico.

A estrutura do livro é anunciada no subtítulo: uma primeira parte que "inclui análises a obras de cinema, de filmes isolados a grupos de filmes de cineastas" (Dias Branco 2016, 17), de Il Postino (1994) e Ossos (1997) a Stanley Kubrick e Michelangelo Antonioni; uma segunda parte que "contém reflexões sobre ideias do cinema, não aquelas desenvolvidas pelos artistas, mas aquelas que emergem da história e prática do cinema e do pensamento que as tenta acompanhar" (id.), da história de um conceito problemático como é a "política dos autores" à "evocação do medo" no cinema de Hideo Nakata.

Se esta antologia de textos assenta em filmes e ideias marcantes para o autor num dado período da sua vida - que podemos situar entre finais dos anos 1990 e inícios do novo milénio -, uma escrita fluida e cuidada torna a obra coesa. Esta é a primeira característica assinalável deste Por Dentro das Imagens: o efeito imersivo de uma escrita que, como nota o autor, cultiva uma certa exigência, herdada das leituras e da experiência como aluno de SDB, mas que evidencia

\footnotetext{
${ }^{1}$ Universidade Nova de Lisboa, Faculdade de Ciências Sociais e Humanas, CIC.Digital, 1069-061, Lisboa, Portugal.
} 
também uma forte consciência do leitor. Nesse sentido, dir-se-ia que esta é uma crítica inteligente no sentido que Jacques Rancière (2010, 57) dá à noção de inteligência: "A inteligência é potência de se fazer compreender, que passa pela verificação do outro." O reconhecimento do leitor também se faz no reconhecimento da sua inteligência. A escrita deste livro permite criar uma plataforma comum construída na base de uma preciosa escolha de palavras.

André Bazin (1992, 110-113) falava da importância de um filme ser funcional. SDB importa esta ideia na sua escrita, que se faz, palavra sobre palavra, como tijolo sobre tijolo, casa de um pensamento posto em comum, isto é, eminentemente comunicável. "Escrevo, e cada palavra discute a ligação inseparável e una entre expressão e conteúdo. Cada frase comenta a minha relação com as obras" (Dias Branco 2016, 148), lê-se no notável texto "O Silêncio dos Olhares." As experiências de crítico, para publicações como a Premiere, e de orador, em apresentações de filmes em espaços públicos ou universitários, conferiram a SDB o poder de simultaneamente, parafraseando Roland Barthes (2007, 74), "desejar a linguagem" e tornar a escrita num diálogo não só com a obra mas também, em primeira instância, com o leitor.

Este livro, como toda a prosa crítica de SDB, é notável por precisamente enformar de um olhar atento, por dentro das imagens dos filmes, e, ao mesmo tempo, por fazer desse olhar um referencial analítico - estético e ético - para o leitor, tornando-o parte ativa no défilement do pensamento crítico. Escreve o autor em "A Política dos Autores, Pensar a Nossa Solidão":

Há quem tenha aprendido, quem continue a aprender, que fazer crítica de cinema é resistir às evidências com a singularidade de uma perspetiva. Essa subjetividade, condição do espectador-participante, atento, responsivo, pede uma expressão - e é esse o trabalho da crítica, que naquilo que faz decide e afirma a importância da própria arte cinematográfica. (Dias Branco 2016, 107)

Neste texto, que sobrevoa a história da cinefilia e crítica moderna, fica patente um desejo de aproximação da criação ao ato de ver e pensar o cinema. Como escreveu Marie-Claire RoparsWuilleumier (1971, 30), "toda a crítica cinematográfica deve ser, antes de tudo, de transcrição, e quiçá também de criação.”

Mas o cinema não se reduz ao cinema. Ele é, como diz JeanLuc Godard em Histoire(s) du cinéma (1988-1998), uma forma que pensa, um inesgotável contentor de ideias: "é vital tornar o cinema uma coisa pensável," escreve SDB $(2016,110)$, antecipando na qualidade de crítico o seu trabalho enquanto investigador e professor. Existe, de facto, nas suas críticas individuais a filmes, esta preocupação com capturar o movimento singular de um pensamento, com ativar em cada filme particular as ideias do cinema e com desvelar nas ideias do cinema os caminhos da nossa relação com o mundo. Penso que o autor não discorda de Alain Badiou $(2013,18)$ quando 
este sustenta, em Cinéma, que "[um] filme é uma proposição no pensamento, um movimento do pensamento, um pensamento conectado, por assim dizer, à sua disposição artística." Como é que o pensamento se movimenta em Por Dentro das Imagens? Por exemplo, SDB fala sobre o poético e o político a propósito do popularíssimo filme de Michael Radford, Il postino; disserta sobre noções de espaço e plano presentes em Ossos e comuns a toda uma geração do cinema português tocada pelos filmes - e pelas lições - de António Reis; perscruta a relação fatídica entre o belo e a criação por via de Morte a Venezia (1971) de Luchino Visconti... o livro avança e a cada análise a um filme descobre-se um trampolim para o pensamento. É isso que importa reter desta experiência de leitura: o pensamento viaja com os filmes e os filmes viajam no pensamento, por vezes, para lá ou aquém - do cinema.

Este "para lá ou aquém do cinema” é outro elemento que anuncia os caminhos que o autor tem trilhado no percurso académico: um entendimento do cinema como um permanente espaço de fronteira entre formas de expressão ou como uma arte de natureza impura. Disse-me na citada entrevista:

Para mim, as coisas estão todas relacionadas e eu tenho a noção de que o interesse principal é o cinema, mas todas essas formas artísticas permitem-nos pensar os seus limites, sem com isto me obrigarem a mim próprio a pensar na suposta essência do cinema. (Mendonça 2016, s/p)

De novo, projectam-se nestas palavras imagens do pensamento de Badiou, para quem o cinema é uma arte paradoxal, em permanente autoquestionamento. Na senda da eterna interrogação baziniana sobre "o que é o cinema?", o filósofo propõe que o cinema é uma "arte ontológica" (Badiou 2013, 207).

O gosto por zonas de fronteira conduziu SDB, no seu doutoramento, a investigar as séries de televisão, depois de ter pesquisado, no âmbito do mestrado, a linguagem dos vídeos musicais, sendo que a sua formação de base é em arquitetura. O cinema aparece, assim, como uma linguagem conciliadora de múltiplas origens, que Badiou define como "uma arte mais um":

O cinema é a sétima arte de uma maneira particular. Ele não se acrescenta às outras artes, permanecendo no mesmo nível que elas. Pelo contrário, ele subentende-as (...). Ele opera sobre as outras artes, usando-as como seus pontos de partida, num movimento que as subtrai de si mesmas. (Badiou 2013, 89)

Independentemente de ser ponto de partida ou ponto de chegada, o cinema é espaço de convergências. SDB é puxado para esta visão ontologizante do cinema quando chama a si obras que integram outras artes ou realizadores que, também eles, são puxados para zonas de fronteira. "Teatro, pintura, música, cinema, Morte a Venezia é tudo isso" (Dias Branco 2016, 34), escreve sobre a obra- 
prima de Visconti feita sob o signo da música de Gustav Mahler e da escrita de Thomas Mann.

Em Antonioni, a tentação de mergulhar nos filmes é acompanhada de outra: a de ir além - ou aquém - deles. Até outras paisagens. "As paisagens da imaginação e do pensamento mostradas na exposição [Le montagne incantate, 1993] são planícies recortadas de Ferrara ou montanhas inventadas. (...) Também as paisagens dos seus filmes são encantadas, fruto de uma visão que absorve e se deixa absorver" (Dias Branco 2016, 89). Antonioni era realizador, mas também era pintor - embora não se visse como tal. O cinema como arte "mais um" é repetidamente posto em evidência neste livro. À guisa dos críticos dos amarelos Cahiers du cinéma, SDB parece partilhar a ideia de que o cinema é "uma arte de síntese - uma arte nova, mas não órfã, porque [pertence] a uma história humana e artística mais vasta" (100).

Lembra SDB, na crítica a Strange Days (1995), que Kathryn Bigelow se formou em pintura pelo San Francisco Art Institute. Talvez seja esse olho pictural de Bigelow que explica o "poder expressivo das imagens e também a paisagem percetiva que algumas delas abrem" (Dias Branco 2016, 57). Este filme aparece em Por Dentro das Imagens como ponto limiar. Nele se celebra o fim de uma era, a vertigem da entrada no novo milénio. Um beijo liga as personagens - e o mundo - a um outro tempo. "Esse beijo é dado já em 2000, o que quer dizer que algo mudou" (Dias Branco 2016, 56). Este filme de desencantada (não) celebração especula sobre o destino da civilização. É o elo que faltava para Por Dentro das Imagens se assumir como uma reflexão basilar acerca de uma certa - ouso defini-la assim - "estética millenial."

A incidência do livro na análise a filmes datados de finais dos anos 1990 permite-nos aceder a um período que, até ver, pareceria estar demasiado próximo para pensarmos nele, ainda que já suficientemente longínquo para entendermos o seu papel determinante no que veio a seguir. Um artigo curto mas importante tem o título "Cinema 1990-99": "Estamos num tempo de contaminações e de vacilações de todos os modelos, referências, e ordens" (Dias Branco 2016, 124). Os filmes atestam isto e, indo mais longe, o leitor interroga-se: de que é feita essa "estética millenial"? Daquilo que SDB escreve a propósito de Abel Ferrara, David Fincher, Kathryn Bigelow e Brian De Palma; por exemplo, de um apetite pela distopia, de um questionamento sobre existências virtuais, hiperrealizadas ou "ecranizadas", de simulações de simulações ou de um virológico decadentismo técnico e humano.

New Rose Hotel (1998) ocupa um lugar especial entre os filmes redescobertos em Por Dentro das Imagens. O facto de ser apenas um de dois filmes - o outro é Ossos de Pedro Costa - que aparecem separadamente em mais do que um texto não deve passar desperce- 
bido. A recensão mais extensa ao subestimado título de Ferrara tem a força da grande crítica: reativa-nos a curiosidade em relação ao que o filme é e ao que o filme pode. Em New Rose Hotel estamos num espaço volatizado pela linguagem veloz e, por vezes, inapreensível da "revolução virtual," que faz diluir no mundo das personagens será já o nosso mundo? - as noções de espaço e de tempo. Tudo se "ecraniza" - a expressão é minha - no universo "hiper-real" de Ferrara, reflexos de reflexos que nos dão a ver, no seu estado convulso, perturbador, desnorteador, a imagem mais nítida destes nossos "estranhos dias."

O que é o contemporâneo? A pergunta levava-nos longe, mas apetece aqui citar o desabafo de Jacques Derrida: “O 'nosso' tempo talvez seja o tempo em que deixou de ser possível dizer com tanta facilidade 'o nosso tempo"' (Derrida e Ferraris 2006, 22). Estes filmes, e SDB é como eles, partilham toda esta - chamemos-lhe assim dificuldade. Neles, nada se fixa. São, portanto, importantes testemunhos "de ombreira" da única coisa que não altera neste nosso tempo que, na realidade, não nos pertence, porque foge velozmente por entre os dedos: o ritmo acelerado da mudança. "A saturação avança contra os limites do humano" (Dias Branco 2016, 126), lê-se no segundo dos "Cinco Detritos."

A escrita projeta-nos rapidamente para as últimas páginas. É assim com os livros que são fáceis de ler e que dão fome ao pensamento. Nós, leitores, vogando nas ideias do cinema, somos levados por um crescendo, que culmina em "Os Sentidos da Cidade" (137). A escrita liberta-se - e fragmenta-se - completamente aqui. O arquiteto SDB $(2016,137)$ pergunta aos filmes que programou num ciclo de cinema, que dá nome ao artigo, o seguinte: "Da cidade, como representa e o que representa um filme?" As obras escolhidas instauram um cânone. A cada filme faz-se associar uma imagem do pensamento. São textos que guardam o movimento mais límpido do olhar de SDB. Lugares onde a crítica atinge a mais elevada dignidade literária. Não espanta que o autor seja um admirador confesso de Bazin, mas também - não menos relevante para o caso - de James Agee e Stanley Cavell.

Em cada fragmento sobre um filme uma reflexão ascende, em espiral, até ao cume das ideias. Por exemplo, sobre Ossos, escreve:

O seu trabalho paciente procura captar o que se revela num olhar furtivo, numa respiração demorada, num gesto cru. Aceita que a linguagem dos corpos é, talvez, anterior a toda a ordem e invenção. Que as suas presenças são os limites do secreto, as manifestações do espírito. (Dias Branco 2016, 139)

SDB regressa ao filme maldito de Ferrara para o habitar de novo - isto é, de modo renovado - com uma prosa luminosa e inspiradora. Em New Rose Hotel, "[há] personagens que são apenas aquilo que um ecrã mostra. Há imagens das cidades que tentam fixar 
a sua estrutura, a sua ordem. Há hierarquias que se diluem, valores que se confundem. Mas o que circula nesta ação é a paixão e o seu jogo" (Dias Branco 2016, 144). A crítica e a cinefilia também são isso: paixão e jogo. Uma dialética do desejo. Por Dentro das Imagens faz-se livro num movimento incessante entre aqueles dois pólos. Um jogo que celebra o ato de fazer, de ver e de partilhar cinema. Parafraseando outra figura tutelar no pensamento de SDB, João Mário Grilo, diria: uma partilha não dos filmes, mas do cinema dos filmes, que é toda uma outra coisa.

\section{BIBLIOGRAFIA}

Badiou, Alain. (2010) 2013. Cinema. Malden e Cambridge: Polity. Barthes, Roland. (1966) 2007. Crítica e Verdade. Lisboa: Edições 70.

Bazin, André. (1958) 1992. O que é o Cinema?. Lisboa: Livros Horizonte.

Derrida, Jacques, e Maurizio Ferraris. (1997) 2006. O Gosto do Segredo. Lisboa: Fim de Século.

Dias Branco, Sérgio. 2016. Por Dentro das Imagens: Obras de Cinema, Ideias do Cinema. Lisboa: Documenta.

Mendonça, Luís. 2016. "Sérgio Dias Branco: 'O cinema constrói um olhar e nós temos de questionar esse olhar'”. Acedido em 27 de março, 2017. http://www.apaladewalsh.com/2016/11/sergio-dias-brancoo-cinema-constroi-um-olhar-e-nos-temos-de-questionar-esseolhar/

Rancière, Jacques. (1987) 2010. O Mestre Ignorante: Cinco lições sobre a emancipação intelectual. Lisboa: Edições Pedago.

Ropars-Wuilleumier, Marie-Claire. (1970) 1971. Ensayos de Lectura Cinematografica. Madrid: Editorial Fundamentos. 